\title{
Chemical changes underlying Dupuytren's
} contracture

\author{
J. VILJANTO, P. O. SEPPÄLÄ, AND A. LEHTONEN \\ Department of Surgery and Department of Medical Chemistry, University of Turku, Turku, Finland
}

The flexion contracture of one or more fingers caused by characteristic changes in the longitudinal fasciculi of the palmar aponeurosis is named after Dupuytren. Histologically, the initial changes consist of cellular proliferations of fibroblastic tissue. The vessels may be prominent, and perivascular accumulations of lymphocytes, monocytes, and plasma cells may be seen. Gradually the vessels become less conspicuous, the leucocytes disappear, and increasing amounts of collagen are deposited within the affected tissues (Klossner, 1945; Skoog, 1948; Ross and Annan, 1951; Mason, 1952). Lagier and Exer (1960) found no difference between the total hydroxyproline content in Dupuytren's contracture (DC) and that in the tendons of the palmaris longus muscle, but the results of glucuronic acid determination led them to suppose a higher polysaccharide content in the contractures. Chemically, they found no difference between the portions of the palmar fascia unaffected by DC and the palmar aponeuroses of normal persons of the same age.

The purpose of this study was to determine the proportions of certain connective tissue components, in order to discover whether there is any resemblance between normal tendon, normal aponeurosis, and the tissue with Dupuytren's contracture. A short preliminary communication has already appeared (Seppälä, Viljanto, and Lehtonen, 1969).

\section{Material}

Samples of palmar fascia were obtained from five patients at operation for DC. Four pieces of normal tendons of palmaris longus muscle, two palmar aponeuroses, one transverse fascia, and one tendon of a flexor muscle were obtained from four patients during tendon transplantation. All the patients were male. The samples were kept frozen at $-15^{\circ} \mathrm{C}$. until analysed. Before analysis the samples were homogenized in distilled water at $+4^{\circ} \mathrm{C}$. in a Bühler rotating-blade disintergrator. About two-thirds of the samples were used for the analyses of glycosaminoglycans (GAG) and one-third for the analysis of collagen fractions.

\section{Case histories}

Case 1, a man aged 51 years, had suffered from a gastric ulcer for over 10 years and from mild cerebral palsy for 3 years before the operation for DC. The symptoms of permanent contraction of the fourth and fifth fingers of the right hand had developed over 3 years.

Case 2, a farmer aged 54 years, had developed contracture of the fourth and fifth fingers of the right hand over 10 years.

Case 3, a man aged 52 years, had developed contracture of the fifth finger over 5 years, with subsequent affection of the third and fourth fingers of the right hand.

Case 4, a man aged 65 years, had symptoms of DC in the left hand of unknown duration.

Case 5, a policeman aged 49 years, had permanent contracture of the ulnar fingers which developed over more than 5 years.

Case 6, a retired fisherman aged 73 years. The tendon of the palmaris longus muscle, the palmar aponeurosis and the tendon of the flexor muscle were taken after amputation of the right arm for a malignant tumour of the humerus.

Case 7, a labourer aged 19 years. The tendon of the palmaris longus muscle was taken in connection with a tendon graft for the flexor tendon of the right index finger.

Case 8, a convict aged 50 years. The tendon of the palmaris longus muscle was taken in connection with a tendon graft for the flexor tendons of the fourth and fifth fingers of the left hand.

Case 9, a plumber aged 63 years. The tendon of the palmaris longus muscle, the palmar aponeurosis and the transverse fascia were taken after amputation of the right arm for malignant tumour.

\section{Methods}

The isolation of collagen fractions and GAGs were carried out by the methods shown in the Figure (overleaf). The specimens were cut into pieces. Homogenization was done at $+4^{\circ} \mathrm{C}$. in a rotating-blade integrator (E. Bühler, Tübingen, West Germany) for $5 \mathrm{~min}$. at $50,000 \mathrm{rev} . / \mathrm{min}$. 


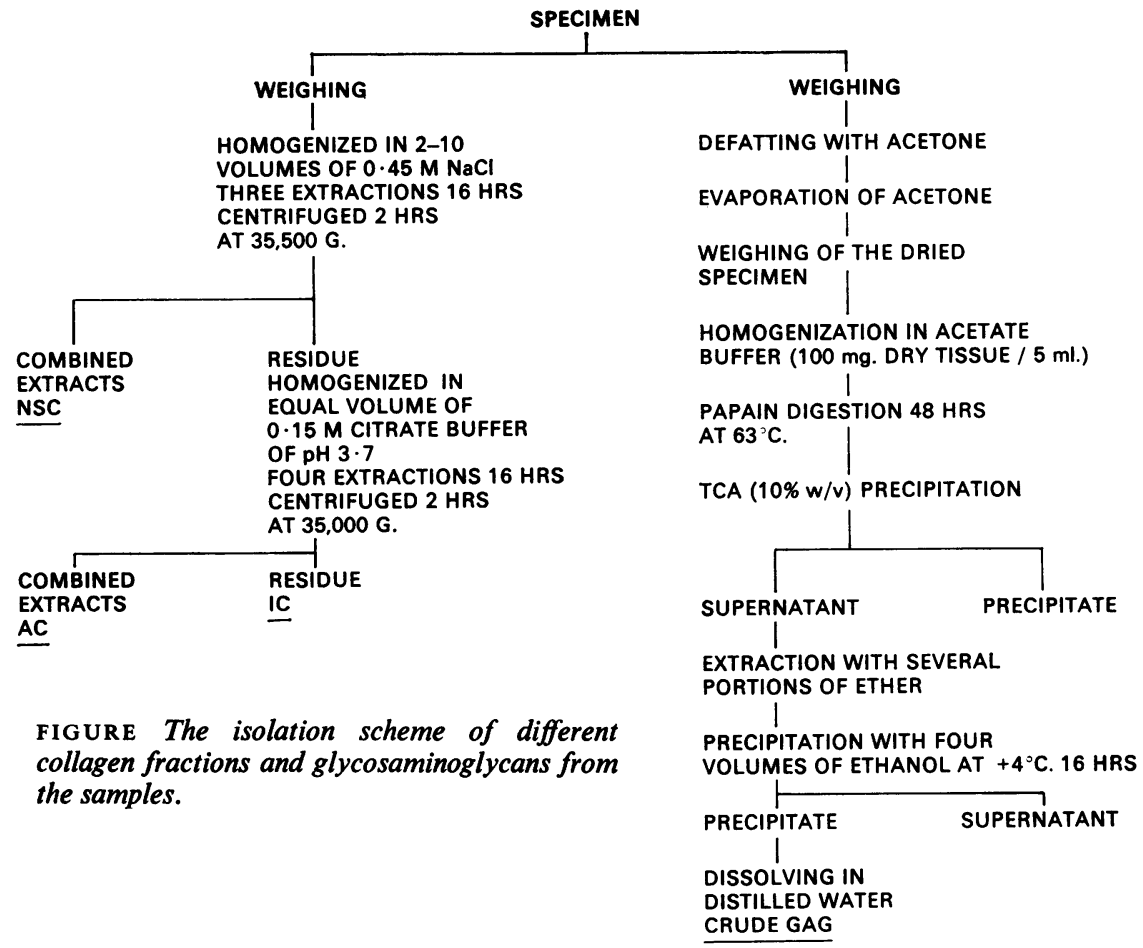

ANALYSIS OF COLLAGEN

Isolation of neutral salt-soluble (NSC), acid-soluble (AC), and insoluble (IC) collagens was carried out at $+4^{\circ} \mathrm{C}$. as described by Pikkarainen (1968) (Figure). After the third extraction only insignificant amounts of NSC were obtained. Hydroxyproline determinations of the collagen fractions were performed by the method of Stegemann (1958) as modified by Woessner (1961).

The samples for the determination of nitrogen were digested by the Kjeldahl method. Nesslerization was carried out as described by Minari and Zilversmit (1963).

ANALYSIS OF GLYCOSAMINOGLYCANS (GAG)

The defatted and dried samples (amount from 51 to $729 \mathrm{mg}$.) were homogenized and digested with papain (Papain Crude Powder, Sigma Chemical Co., St. Louis, Missouri, U.S.A.) as described by Schiller, Slover, and Dorfman (1961). Trichloroacetic acid (TCA) was added to precipitate residual proteins and nucleic acids. The excess of trichloroacetic acid was removed from the supernatant by extraction with ether. The GAGs were precipitated for at least $16 \mathrm{hrs}$ at $+4^{\circ} \mathrm{C}$. with a fourfold volume of 96 per cent. ethanol containing 0.5 per cent. of sodium acetate. The precipitate after centrifugation and dissolving in distilled water was hydrolyzed for hexosamine analysis in $2 \mathrm{~N}$ hydrochloric acid at $103^{\circ} \mathrm{C}$. for $17 \mathrm{hrs}$. This time was found to give the best colour development in preliminary experiments. The hexos- amines were separated from interfering chromogens by means of Dowex 50 according to Boas (1953). The colour reaction was obtained by the Elson-Morgan method, modified by Blix (1948).

The hexosamine content of the supernatant after $\frac{0}{5}$ ethanol precipitation was determined after evaporation 3 of ethanol. The hexosamine content of the TCA preci- $\delta$ pitate was also determined. The results of these hexosamine determinations give the protein hexosamine.

The ratio of galactosamine to glucosamine in isolated GAG specimens was determined by gas chromatography, $\frac{D}{O}$ employing a modification of the method of Kärkkäinen, Lehtonen, and Nikkari (1965).

Electrophoretic fractionation of the crude GAGs was ${ }^{\circ}$ performed in Oxoid cellulose acetate sheets at $\mathrm{pH} 8.6$ as $N$ described by Näntö (1963). Reference compounds were ${ }_{\mathrm{C}}^{N}$ the same as used by Lehtonen (1968).

Because there were great differences in the dehydration of the samples analysed, the contents of hexosamines and collagen were calculated in relation to the nitrogen content of the samples.

Student's t-test was applied for determining the $\frac{T}{T}$ significance of the difference between two means.

\section{Results}

The average relative content of total collagen was $\Omega$ not significantly higher in specimens from patients 
with Dupuytren's contracture than in tendons of the palmaris longus muscle (Table I). The specimens involved by $D C$ showed a significantly lower $(P<0.005)$ relative content of NSC than the tendons of the palmaris longus muscle, whereas that of AC did not vary significantly in these tissues. The relative content of IC was slightly higher in DC specimens than in the tendons of the palmaris longus muscle. Analyses of the palmar aponeuroses showed that the relative amount of NSC was higher than in DC specimens.

The content of hexosamine in the crude GAGs was significantly higher $(P<0.05)$ in the DC specimens than in the tendons of the palmaris longus muscle (Table II). The absolute amounts of galactosamine $(14.0 \mu \mathrm{g} . / \mathrm{mg}$. total $\mathrm{N})$ and glucosamine $(6.1 \mu \mathrm{g} . / \mathrm{mg}$. total $\mathrm{N})$ in the crude GAGs obtained from the tissues involved by $\mathrm{DC}$ were also

Table I Content of collagen and various collagen fractions in samples analysed

\begin{tabular}{|c|c|c|c|c|}
\hline Group & $\begin{array}{l}\text { Case } \\
\text { no. }\end{array}$ & $\begin{array}{l}\text { Collagen nitrogen } \\
\text { as per cent. } \\
\text { of total nitrogen }\end{array}$ & $\begin{array}{l}\text { NSC* } \\
\text { as per cent. } \\
\text { of total collagen }\end{array}$ & $\begin{array}{l}A C^{*} \\
\text { as per cent. } \\
\text { of total collagen }\end{array}$ \\
\hline A. Dupuytren's contracture & $\begin{array}{l}1 \\
2 \\
3 \\
4 \\
5\end{array}$ & $\begin{array}{l}67 \\
91 \\
69 \\
85 \\
6876 \cdot 0 \pm 11 \cdot 2 \\
\end{array}$ & $\begin{array}{l}1 \cdot 5 \\
1 \cdot 2 \\
1 \cdot 9 \\
1 \cdot 2 \\
1 \cdot 5 \quad 1 \cdot 46 \pm 0 \cdot 29\end{array}$ & $\begin{array}{l}0.8 \\
0.5 \\
0.7 \\
0.5 \\
0.9 \quad 0.68 \pm 0.18 \\
\end{array}$ \\
\hline $\begin{array}{l}\text { B. Tendon of palmaris longus } \\
\text { muscle }\end{array}$ & $\begin{array}{l}6 \\
7 \\
8 \\
9\end{array}$ & $\begin{array}{l}68 \\
61 \\
64 \\
7166 \cdot 0 \pm 4 \cdot 4\end{array}$ & $\begin{array}{l}1 \cdot 9 \\
2 \cdot 3 \\
2 \cdot 4 \\
2 \cdot 2 \\
\end{array}$ & $\begin{array}{l}0.5 \\
0.5 \\
1 \cdot 2 \\
0.40 .65 \pm 0.37\end{array}$ \\
\hline C. Palmar aponeurosis & $\begin{array}{l}6 \\
9\end{array}$ & $\begin{array}{l}78 \\
5265 \cdot 0\end{array}$ & $\begin{array}{l}3 \cdot 6 \\
2 \cdot 2\end{array} 2 \cdot 90$ & $\begin{array}{l}0.5 \\
1.0 \\
1.75\end{array}$ \\
\hline D. Transverse fascia & 9 & 73 & $1 \cdot 0$ & $0 \cdot 4$ \\
\hline E. Flexor tendon & 6 & 72 & $1 \cdot 7$ & 0.6 \\
\hline
\end{tabular}

Mean \pm SD shown in bold type

* NSC $=$ Neutral salt-soluble collagen. AC = Acid-soluble collagen.

† Significance $(P<0.005)$ in relation to Group $A$.

Table II Content of various hexosamine-containing fractions in samples analysed

\begin{tabular}{|c|c|c|c|c|c|}
\hline \multirow[t]{2}{*}{ Group } & \multirow{2}{*}{$\begin{array}{l}\text { Case } \\
\text { no. }\end{array}$} & \multirow{2}{*}{$\begin{array}{l}\text { Protein hexosamine } \\
(\mu g . / m g . \text { total } N)\end{array}$} & \multicolumn{2}{|l|}{ GAG-hexosamine } & \multirow{2}{*}{$\begin{array}{l}\text { Molar ratio of } \\
\text { GAG-galactosamine } \\
\text { to } \\
G A G \text {-glucosamine }\end{array}$} \\
\hline & & & ( $\mu g . / m g$. collagen $)$ & $(\mu g . / m g$. total $N)$ & \\
\hline $\begin{array}{l}\text { A. Dupuytren's } \\
\text { contracture }\end{array}$ & $\begin{array}{l}1 \\
2 \\
3 \\
4 \\
5\end{array}$ & $\begin{array}{r}21 \cdot 5 \\
13 \cdot 4 \\
8 \cdot 8 \\
7 \cdot 0 \\
9 \cdot 6 \quad 12 \cdot 1 \pm 5 \cdot 8\end{array}$ & $\begin{array}{l}3 \cdot 9 \\
1 \cdot 7 \\
4 \cdot 1 \\
6 \cdot 5 \\
8 \cdot 3 \quad 4 \cdot 90 \pm 2 \cdot 54\end{array}$ & $\begin{array}{r}14 \cdot 4 \\
8 \cdot 7 \\
15 \cdot 5 \\
30 \cdot 7 \\
31 \cdot 1 \quad 20 \cdot 1 \pm 10 \cdot 2\end{array}$ & $\begin{array}{l}2 \cdot 7 \\
1 \cdot 2 \\
2 \cdot 3 \\
1 \cdot 2 \\
3 \cdot 62 \cdot 20 \pm 1 \cdot 03\end{array}$ \\
\hline $\begin{array}{l}\text { B. Tendon of } \\
\text { palmaris longus } \\
\text { muscle }\end{array}$ & $\begin{array}{l}6 \\
7 \\
8 \\
9\end{array}$ & $\begin{array}{l}5 \cdot 7 \\
8 \cdot 7 \\
5 \cdot 5 \\
7 \cdot 7 \quad 6 \cdot 9 \pm 1 \cdot 6\end{array}$ & $\begin{array}{l}1 \cdot 5 \\
2 \cdot 9 \\
1 \cdot 8 \\
1 \cdot 2 \quad 1 \cdot 85 \pm 0 \cdot 74^{*}\end{array}$ & $\begin{array}{l}5 \cdot 6 \\
9 \cdot 7 \\
6 \cdot 3 \\
4 \cdot 8 \quad 6 \cdot 6 \pm 2 \cdot 2^{*}\end{array}$ & $\begin{array}{l}4 \cdot 6 \\
3 \cdot 0 \\
6 \cdot 0 \\
-4 \cdot 53 \pm 1 \cdot 50^{*}\end{array}$ \\
\hline $\begin{array}{l}\text { Palmar } \\
\text { aponeurosis }\end{array}$ & $\begin{array}{l}6 \\
9\end{array}$ & $\begin{array}{l}6 \cdot 7 \\
8 \cdot 87 \cdot 8\end{array}$ & $\begin{array}{l}1 \cdot 3 \\
3 \cdot 7 \\
2 \cdot 50\end{array}$ & $\begin{array}{l}5 \cdot 5 \\
10 \cdot 58 \cdot 0\end{array}$ & $\begin{array}{l}2 \cdot 1 \\
1 \cdot 2 \\
1 \cdot 65\end{array}$ \\
\hline D. Transverse fascia & 9 & $13 \cdot 2$ & $2 \cdot 3$ & $9 \cdot 3$ & $1 \cdot 0$ \\
\hline E. Flexor tendon & 6 & $3 \cdot 7$ & $1 \cdot 4$ & $5 \cdot 6$ & $2 \cdot 6$ \\
\hline
\end{tabular}


higher than the corresponding figures in the palmar tendons $(5.4$ and $1.2 \mu \mathrm{g}$./mg. total $\mathrm{N})$ or in the palmar aponeuroses $(5.0$ and $3.0 \mu \mathrm{g} . / \mathrm{mg}$. total $\mathrm{N})$. The ratio of galactosamine to glucosamine was lower $(P<0.05)$ in contractures than in tendons of the palmaris longus muscle. The corresponding analytical results of two palmar aponeuroses were lower than those of DC specimens.

Electrophoresis of the crude GAGs on cellulose acetate showed a fraction with electrophoretic mobility equal to that of sulphated galactosaminoglycans. This was observed in all specimens. A weakly staining fraction which moved at the same rate as hyaluronate was seen on the electrophoresis of GAGs of contractures and in most samples of tendons and palmar aponeuroses. The third more weakly staining fraction moving at the same rate as the reference samples of keratosulphate, and heparitin sulphate was seen in most specimens. No attempt was made to identify these fractions further, because of the small amount of samples.

No differences were observed in the GAGcontents of transverse fascia as compared with that of normal palmar aponeurosis, whereas the total collagen content seems to be higher (Case 9).

\section{Discussion}

Dorner (1968) has demonstrated the changes in glycosaminoglycan and collagen composition during the regeneration period of the rabbit tendon. According to his results, hyaluronate is the principal glycosaminoglycan in young regenerating tendons, while dermatan sulphate is the main glycosaminoglycan in old regenerating tendons, the composition of which also approximates closely to that of mature tendons. The content of sulphated GAGs in mature tendons was 84 per cent. of the total GAGs. Molar ratios of hexosamine/hydroxyproline decreased during regeneration of the tendons.

Our results show higher hexosamine contents and higher hexosamine/hydroxyproline ratios in Dupuytren's contracture than in normal palmar aponeuroses and in tendons of palmaris longus muscle. The galactosamine/glucosamine molar ratios and electrophoretic analyses suggest that sulphated galactosaminoglycans seem to be the principal GAG in all specimens analysed. From these ratios the amount of sulphated galactosaminoglycans relative to total GAGs can be calculated to be about 60 per cent. in DC specimens and about 80 per cent. in the tendons of the palmaris longus muscle. Thus the composition of GAG in contractures appears to resemble that of regenerating tendons. The tendon of normal palmaris longus muscle obtained from a 19-year-old youth (Case 7) shows similarities in the content and composition of GAGs with the DC specimens from older patients. These biochemical observations support our conception of continuous regenerative processes in Dupuytren's contracture.

Skoog (1948) supposed that the strain to which certain elements of the aponeurosis are subjected played an essential role in the pathogenesis of Dupuytren's contracture, and that the disease originated in fibrillar ruptures within the aponeurosis. He later expressed the opinion that the pathological process itself was in essence the same as that occurring in scar formation and contracture (Skoog, 1967). Our results are in agreement with Skoog's histological findings and his hypothesis of multiple minor regenerating centres.

\section{Summary}

The contents of glycosaminoglycans and collagen fractions in five human palmar aponeuroses with Dupuytren's contracture were compared with corresponding components in normal palmar aponeuroses, and in palmar and flexor tendons. The content of total collagen and the relative content of acid-soluble collagen were equal in specimens from patients with Dupuytren's contracture and in control specimens, whereas the relative content of neutral salt-soluble collagen was less in the former. The amount of glycosaminoglycans was higher in cases of Dupuytren's contracture than in controls. The relative amount of galactosamine-containing glycosaminoglycans was higher in the control than in the specimens involved by Dupuytren's contracture.

The investigation was aided by a grant from the Emil Aaltonen Foundation. J.V. wishes to express his deep gratitude to Prof. Tord Skoog, M.D., for fruitful discussions concerning Dupuytren's contracture.

\section{References}

Bux, G. (1948) Acta chem. scand., 2, 467 (The determination of hexosamines according to Elson and Morgan).

BoAs, N. F. (1953) J. biol. Chem., 204, 553 (Method for the determination of hexosamines in tissue).

DORNER, R. W. (1968) Arch. Biochem., 128, 34 (Changes in glycosaminoglycan composition associated with maturation of regenerating rabbit tendon).

KärkKäInen, J., Lehtonen, A., AND NixkARI, T. (1965) J. Chromatogr., 20, 457 (Determination of glucosamine and galactosamine by gas chromatography).

Klossner, A. R. (1945) Acta Soc. Med. fenn. "Duodecim," Ser. B 34, Fasc. 2, p. 1 (Dupuytrensche Kontraktur bei derselben Person gleichzeitig in beiden Händen und im linken Fuss). 
LAGIER, R., AND EXER, B. (1960) Virchows Arch. path. Anat., 333, 68 (Uber chemische Untersuchungen der sehnenförmigen Stränge bei der Dupuytrenschen Kontraktur. Vergleichende Untersuchungen an verschiedenen Arten normalen Bindegewebes der Hand).

Lehtonen, A. (1968) Acta physiol. scand., Suppl. 310 (The mucopolysaccharides in ageing experimental granulation tissue).

Mason, M. L. (1952) Arch. Surg., 65, 457 (Dupuytren's contracture).

MinARI, O., AND ZILVERSMT, D. B. (1963) Analyt. Biochem., 6, 320 (Use of KCN for stabilization of color in direct Nesslerization of Kjeldahl digests).

NÄNTö, V. (1963) Acta chem. scand., 17, 857 (On the electrophoretic separation of acid mucopolysaccharides on cellulose acetate sheets).

Pikkarainen, J. (1968) Acta physiol. scand., Suppl. 309 (The molecular structures of vertebrate skin collagens. A comparative study).

Ross, J. A., ANd ANnan, J. H. (1951) Ann. Surg., 134, 186 (Dupuytren's contracture).

SCHILler, S., Slover, G. A., AND Dorfman, A. (1961) J. biol. Chem., 236, 983 (A method for the separation of acid mucopolysaccharides: its application to the isolation of heparin from the skin of rats).

SeppälÄ, P. O., Viluanto, J., AND Lehtonen, A. (1969) Scand. J. clin. Lab. Invest., 23, Suppl. 108, p. 23 (The components of connective tissue in Dupuytren's contractures).

Sxoog, T. (1948) Acta chir. scand., 96, Suppl. 139 (Dupuytren's contraction, with special reference to aetiology and improved surgical treatment).

- (1967) Surg. clin. N. Amer., 47, 433 (Dupuytren's contracture: pathogenesis and surgical treatment).

Stegemann, H. (1958) Hoppe-Seyler's Z. physiol. Chem., 311, 41 (Mikrobestimmung von Hydroxyprolin mit Chloramin-T und $p$-Dimethylamino-benzaldehyd).

WOESSNER, J. F., JR. (1961) Arch. Biochem., 93, 440 (The determination of hydroxyproline in tissue and protein samples containing small proportions of this imino acid). 